\title{
Monoamine Oxidase-A Inhibition and Associated Antioxidant Activity in Plant Extracts with Potential Antidepressant Actions
}

\author{
Tomás Herraiz (i) and Hugo Guillén \\ Instituto de Ciencia y Tecnología de Alimentos y Nutrición (ICTAN), Spanish National Research Council (CSIC), \\ Juan de la Cierva 3, 28006 Madrid, Spain
}

Correspondence should be addressed to Tomás Herraiz; therraiz@ictan.csic.es

Received 3 August 2017; Accepted 12 December 2017; Published 15 January 2018

Academic Editor: Pierluigi Di Ciccio

Copyright (C) 2018 Tomás Herraiz and Hugo Guillén. This is an open access article distributed under the Creative Commons Attribution License, which permits unrestricted use, distribution, and reproduction in any medium, provided the original work is properly cited.

\begin{abstract}
Monoamine oxidase (MAO) catalyzes the oxidative deamination of amines and neurotransmitters and is involved in mood disorders, depression, oxidative stress, and adverse pharmacological reactions. This work studies the inhibition of human MAO-A by Hypericum perforatum, Peganum harmala, and Lepidium meyenii, which are reported to improve and affect mood and mental conditions. Subsequently, the antioxidant activity associated with the inhibition of MAO is determined in plant extracts for the first time. $H$. perforatum inhibited human MAO-A, and extracts from flowers gave the highest inhibition $\left(\mathrm{IC}_{50}\right.$ of $\left.63.6 \mu \mathrm{g} / \mathrm{mL}\right)$. Plant extracts were analyzed by HPLC-DAD-MS and contained pseudohypericin, hypericin, hyperforin, adhyperforin, hyperfirin, and flavonoids. Hyperforin did not inhibit human MAO-A and hypericin was a poor inhibitor of this isoenzyme. Quercetin and flavonoids significantly contributed to MAO-A inhibition. P. harmala seed extracts highly inhibited MAO-A (IC ${ }_{50}$ of $49.9 \mu \mathrm{g} / \mathrm{L}$ ), being a thousand times more potent than $H$. perforatum extracts owing to its content of $\beta$-carboline alkaloids (harmaline and harmine). L. meyenii root (maca) extracts did not inhibit MAO-A. These plants may exert protective actions related to antioxidant effects. Results in this work show that $P$. harmala and $H$. perforatum extracts exhibit antioxidant activity associated with the inhibition of MAO (i.e., lower production of $\mathrm{H}_{2} \mathrm{O}_{2}$ ).
\end{abstract}

\section{Introduction}

The enzyme monoamine oxidase (MAO) metabolizes xenobiotic and endogenous amines and neurotransmitters including serotonin, dopamine, norepinephrine, tyramine, tryptamine, and the neurotoxin MPTP $[1,2]$. It occurs as two isoenzymes, MAO-A and MAO-B, which play an important role in the central nervous system (CNS) and peripheral organs. MAO-B is involved in neurodegenerative diseases and $\mathrm{MAO}-\mathrm{A}$ in psychiatric conditions and depression. Inhibitors of MAO-B are useful as neuroprotectants, whereas inhibitors of MAO-A are effective antidepressants although their use may trigger adverse reactions (e.g., hypertensive crisis with foods containing tyramine) [1]. On the other hand, the oxidation of biogenic amines and neurotransmitters by $\mathrm{MAO}$ enzymes generates hydrogen peroxide $\left(\mathrm{H}_{2} \mathrm{O}_{2}\right)$, oxygen radicals, and aldehydes, which are risk factors for cell oxidative injury. Therefore, the inhibition of MAO may result in protection against oxidative stress and neurotoxins $[1,3,4]$.
Recent investigations have pointed out that plant and food extracts may inhibit MAO enzymes resulting in the abovementioned biological effects [3,5-14]. On the other hand, as a result of MAO inhibition, those products might be involved in undesirable interactions with other herbal preparations, foods, or drugs [1].

Hypericum perforatum L. (family Hypericaceae) (St. John's wort) is widely used for health purposes and their products are commercially available as herbs, nutraceuticals, teas, tinctures, juices, oily macerates, phytopharmaceuticals, and food additives and supplements $[15,16]$. H. perforatum is popular for treatment of mild and moderate depression [1719]. It may trigger adverse pharmacological interactions with others herbs, drugs, or foods [20-22]. Its ability to alleviate and improve mood disorders and depression is attributed to active compounds that exhibit antidepressant properties [23, 24]. The most accepted mechanism of action is monoamine reuptake inhibition but additional mechanisms including monoamine oxidase inhibition and synergistic effects can 
be involved [17]. Peganum harmala (family Zygophyllaceae) and Lepidium meyenii (family Brassicaceae) (maca) are plants with CNS effects and potential antidepressant actions [14, 25, 26]. P. harmala, native from the Mediterranean region and Asia and extended to North America areas, is used as a multipurpose health remedy including CNS disorders. Preparations of this plant may trigger adverse pharmacological interactions [27]. L. meyenii is an edible plant from the central Andes whose roots are used as a food energizer and nutraceutical to improve physical and mental conditions and fertility [28]. The purpose of this work was to study the inhibition of human MAO-A by extracts of $H$. perforatum, P. harmala, and L. meyenii (maca) as well as by their active components that were identified and analyzed by HPLCDAD-MS and subsequently evaluate the antioxidant activity which is specifically associated with the inhibition of MAO. This specific antioxidant activity is determined for the first time in plant extracts.

\section{Materials and Methods}

Hypericum perforatum L. plants collected in Ciudad Real (Spain) were dried and separated in parts: flowers; top aerial portions of the plant including branched stems and leaves but no flowers; and main stems (central and lower) and roots. They were ground and the powder used for sample preparation. Commercial herbs and herbal supplements (capsules and tablets) of $H$. perforatum were also purchased in local herbal shops. Peganum harmala L. plant and seeds were collected in Toledo (Spain). Lepidium meyenii (maca) both as powder and commercial tablets were obtained from Peru and local shops. Hypericin standard (>95\% purity by HPLC) from HWI Analytik GMBH pharma solutions, hyperforin dicyclohexylammonium salt, quercetin, harmaline, harmine, catalase, clorgyline, 3,3',5,5'-tetramethylbenzidine (TMB), and horseradish peroxidase (HRP) type II were purchased from Sigma-Aldrich.

2.1. Sample Preparation of Plant Extracts. Samples containing $H$. perforatum (i.e., plant parts, herbal preparation, capsules, or tablets) $(500 \mathrm{mg})$ were homogenized in $10 \mathrm{~mL}$ of water/methanol $(1: 1)$ by using an Ultra Turrax homogenizer, centrifuged at $10000 \mathrm{rpm}$ for $10 \mathrm{~min}$, and the supernatant was collected. The process was repeated twice with the residue and the three supernatant fractions collected, mixed and analyzed by HPLC as mentioned below. After three consecutive extractions, the recoveries of hypericin and pseudohypericin were higher than $97 \%$. Samples of L. meyenii (maca) $(500 \mathrm{mg}$ ) and $P$. harmala seeds $(500 \mathrm{mg})$ were homogenized, respectively, in $10 \mathrm{~mL}$ of water/methanol $(1: 1)$ or $10 \mathrm{~mL}$ of $0.6 \mathrm{M}$ perchloric acid: methanol $(1: 1)$ by using an Ultra Turrax homogenizer, centrifuged at $10000 \mathrm{rpm}$ for $10 \mathrm{~min}$, and the supernatant was collected. This process was repeated twice with the residue and the collected supernatants were mixed and analyzed by HPLC as mentioned below.

2.2. RP-HPLC Analysis of Plant Extracts. The analysis of $H$. perforatum extracts was performed by RP-HPLC with UV diode array and fluorescence detection using a HPLC
1050 (Agilent) coupled with a 1100 diode array detector (DAD) (Agilent) and a 1046A-fluorescence detector. A $150 \times$ $3.9 \mathrm{~mm}$ i.d., $4 \mu \mathrm{m}$, Nova-pak C18 column (Waters) was used for separation. Chromatographic conditions were $50 \mathrm{mM}$ ammonium phosphate buffer ( $\mathrm{pH} 3$ ) (buffer A) and $20 \%$ of $\mathrm{A}$ in acetonitrile (buffer $\mathrm{B}$ ). The gradient was programmed from $0 \%(100 \% \mathrm{~A})$ to $32 \% \mathrm{~B}$ in $8 \mathrm{~min}$ and $100 \% \mathrm{~B}$ at $10 \mathrm{~min}$. The flow rate was $1 \mathrm{~mL} / \mathrm{min}$, the column temperature was $40^{\circ} \mathrm{C}$, and the injection volume was $20 \mu \mathrm{L}$. Detection of hypericins was carried out by absorbance at $590 \mathrm{~nm}$ and fluorescence at $236 \mathrm{~nm}$ for excitation and $592 \mathrm{~nm}$ for emission. The concentration of hypericin was determined from a calibration curve of response (absorbance at $590 \mathrm{~nm}$ ) versus concentration with solutions made in the laboratory from hypericin standard. The same response factor was applied to pseudohypericin, protohypericin, and protopseudohypericin. Flavonoids and flavonoid glycosides were analyzed at $265 \mathrm{~nm}$ and $355 \mathrm{~nm}$ and the concentration of quercetin was determined at $355 \mathrm{~nm}$ from a calibration curve of response versus concentration. The HPLC fraction corresponding to flavonoids and flavonoid glycosides (7 to $11 \mathrm{~min}$ ) was collected by successive injections of $H$. perforatum extract (herbs) and, after evaporation in vacuum, dissolved in 30\% methanol and used for MAO-A inhibition. The phloroglucinols (hyperforin, adhyperforin, hyperfirin, and adhyperfirin) were analyzed at $280 \mathrm{~nm}$ by using the same column (Novapak C18) and conditions but under isocratic elution with $20 \%$ of $50 \mathrm{mM}$ ammonium phosphate buffer, $\mathrm{pH} 3$, and $80 \%$ of acetonitrile. The concentration of these compounds was determined from a calibration curve of hyperforin standard. The analysis of $\beta$-carboline alkaloids in P. harmala and $L$. meyenii was carried out as previously described [14, 29].

2.3. Identification by HPLC-ESI-Mass Spectrometry. Identification of compounds in $H$. perforatum extracts was done by HPLC-MS (electrospray-negative ion mode) by using a 1200 series HPLC-DAD coupled to a 6110 quadrupole-MS (Agilent). Chromatographic separation was performed on a $150 \times 2.1 \mathrm{~mm}$ i.d. Zorbax SB-C18 $(5 \mu \mathrm{m})$ column (Agilent Technologies). The chromatographic conditions were eluent A: formic acid $(0.1 \%)$; B: formic acid $(0.1 \%)$ in acetonitrile; gradient: $0 \%$ to $70 \% \mathrm{~B}$ in $8 \mathrm{~min}$ and $100 \% \mathrm{~B}$ at $10 \mathrm{~min}$, flow rate: $0.3 \mathrm{~mL} / \mathrm{min} ; \mathrm{T}: 40^{\circ} \mathrm{C}$; mass range: $50-700 \mathrm{u}$, and cone voltage: $150 \mathrm{~V}$. For identification of phloroglucinols (e.g., hyperforin), separation was done using a Nova-pak C18 $(4 \mu \mathrm{m})$ column with the same eluents and isocratic elution (eluent $\mathrm{A}, 20 \%$ and eluent $\mathrm{B}, 80 \%$ ) at a flow rate of $0.7 \mathrm{~mL} / \mathrm{min}$ and mass spectra recorded in negative and positive ionization. Identification of compounds was done on the basis of mass spectra, UV-vis spectra (DAD) of chromatographic peaks, and coelution with standards. $\beta$ Carbolines in P. harmala and L. meyenii were identified as previously described [14, 29].

2.4. Monoamine Oxidase (MAO-A) Inhibition Assays. MAO assays were performed as elsewhere $[8,11,14]$. Briefly, membrane protein fractions containing MAO-A (BD-Gentest) were diluted to the desired concentrations in $100 \mathrm{mM}$ potassium phosphate buffer ( $\mathrm{pH} 7.4)$. A $0.2 \mathrm{~mL}$ reaction mixture 


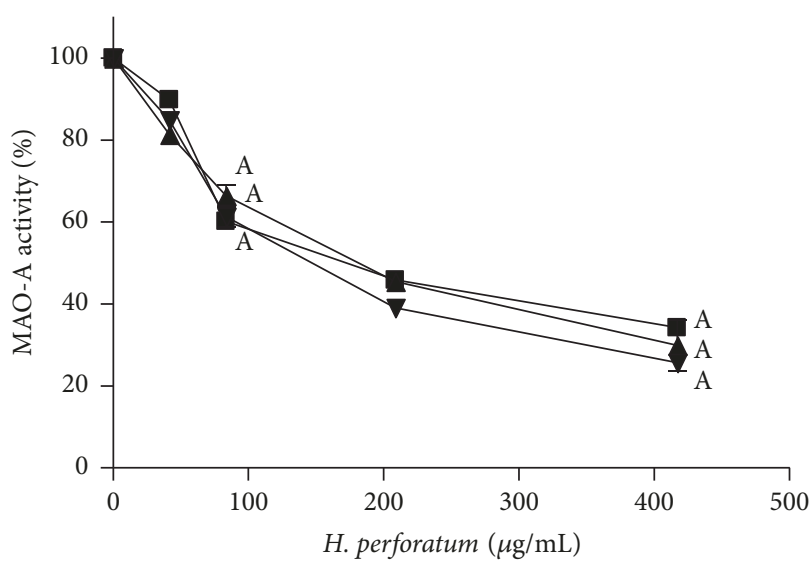

(a)

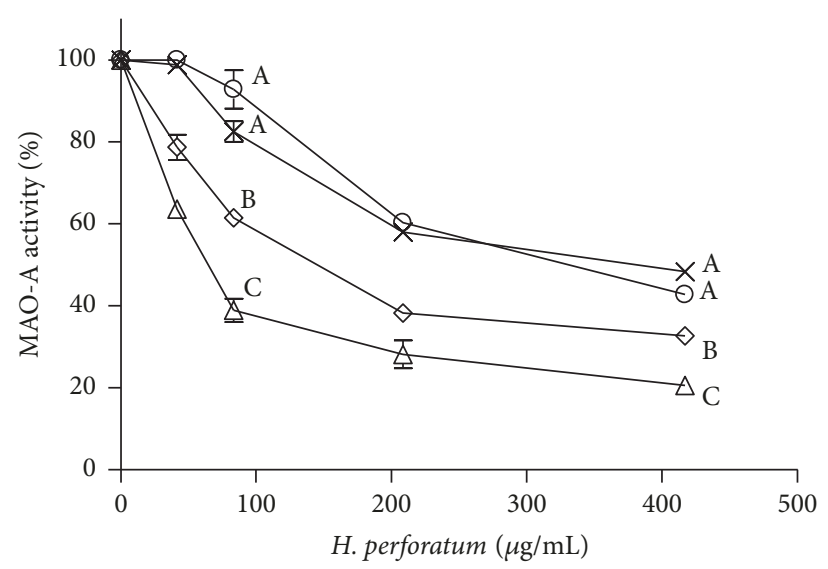

(b)

FIGURE 1: Inhibition of human monoamine oxidase-A (MAO-A) by extracts of commercial preparations of H. perforatum (a) (capsules, $\mathbf{\square}$; tablets, $\mathbf{\Delta}$; herbs, $\boldsymbol{\nabla})$, and extracts from different parts of the plant (b) (flowers, $\triangle$; top stems, $\diamond$; main stems (central), $\times ;$ roots, $\bigcirc)$. Significant differences $(p<0.05)$ among extracts at a selected concentration are indicated with different letters.

containing $0.01 \mathrm{mg} / \mathrm{mL}$ protein and $0.25 \mathrm{mM}$ kynuramine in $100 \mathrm{mM}$ potassium phosphate $\left(\mathrm{pH} \mathrm{7.4)}\right.$ was incubated at $37^{\circ} \mathrm{C}$ for $40 \mathrm{~min}$. After incubation, the reaction was stopped by the addition of $2 \mathrm{~N} \mathrm{NaOH}(75 \mu \mathrm{L})$, followed by the addition of $70 \% \mathrm{HClO}_{4}(25 \mu \mathrm{L})$, and the sample was centrifuged $(10000 \mathrm{~g})$ for $10 \mathrm{~min}$. The supernatant $(20 \mu \mathrm{L})$ was injected into the HPLC and the deamination product of kynuramine (i.e., 4-hydroxyquinoline) formed during enzymatic reaction determined by RP-HPLC-diode array detection at $320 \mathrm{~nm}$. A response curve of area versus concentration was constructed to calculate the concentration of 4-hydroxyquinoline. In order to perform assays of MAO inhibition, aliquots of extracts from plants or commercial preparations or instead pure compounds were conveniently diluted and added to reaction mixtures containing kynuramine $(0.25 \mathrm{mM})$ and MAO-A $(0.01 \mathrm{mg} / \mathrm{mL}$ protein) in $100 \mathrm{mM}$ potassium phosphate buffer ( $\mathrm{pH} 7.4$ ), with enzymatic reaction and analysis carried out as above, and compared with the corresponding controls containing solvent. The standard inhibitor clorgyline was used as a positive control for inhibition ( $>90 \%$ inhibition at $2.5 \mu \mathrm{M})$. Incubations were carried out at least in duplicate from different experiments and the $\mathrm{IC}_{50}$ values were calculated using GraphPad Prism 4.0.

2.5. Determination of Antioxidant Activity Associated with Monoamine Oxidase (MAO) Inhibition. Assays $(0.2 \mathrm{~mL})$ of reaction mixtures in $70 \mathrm{mM}$ potassium phosphate buffer $(\mathrm{pH}$ 7.4), containing $0.025 \mathrm{mg} / \mathrm{mL} \mathrm{MAO}-\mathrm{A}$ protein and $0.25 \mathrm{mM}$ kynuramine, were incubated at $37^{\circ} \mathrm{C}$ for $40 \mathrm{~min}$ in the absence (control assays) or in the presence of plant extracts. MAO assays were also performed in presence of clorgyline $(25 \mu \mathrm{M})$, a classical inhibitor of MAO-A (positive control of inhibition), or catalase enzyme $(100 \mu \mathrm{g} / \mathrm{mL})$. After the incubation period, the reaction mixture was added with activated charcoal $(3.5 \mathrm{mg})$, mixed, and filtered $(0.45 \mu \mathrm{m})$. The solution was added with $20 \mu \mathrm{L}$ of $10 \mathrm{mM}$ tetramethylbenzidine (TMB) in $40 \%$ DMSO and $20 \mu \mathrm{L}$ of horseradish peroxidase (HRP) type II $(1 \mathrm{mg} / \mathrm{mL})$, kept $5 \mathrm{~min}$, and added with $0.3 \mathrm{~mL}$ of $0.5 \mathrm{M} \mathrm{H}_{2} \mathrm{SO}_{4}$ solution. The absorbance at $450 \mathrm{~nm}$ was measured to determine TMB diimine, a yellow product resulting from the oxidation of TMB by HRP and the $\mathrm{H}_{2} \mathrm{O}_{2}$ generated in the oxidative deamination catalyzed by MAO. The oxidation of TMB in the presence of inhibitors of MAO was compared with the corresponding controls without inhibitors and appropriate blanks showed absence of interferences.

\section{Results and Discussion}

Commercial preparations of $H$. perforatum inhibited human MAO-A with similar potency: IC $_{50}$ values of $142.3 \pm$ $30.6 \mu \mathrm{g} / \mathrm{mL}$ (herbal preparation), $193 \pm 61 \mu \mathrm{g} / \mathrm{mL}$ (capsules), and $173 \pm 29 \mu \mathrm{g} / \mathrm{mL}$ (tablets) (Figure 1(a)). Regarding plants, $H$. perforatum extracts from flowers afforded the highest inhibition ( $\mathrm{IC}_{50}$ of $63.6 \pm 9.4 \mu \mathrm{g} / \mathrm{mL}$ ) followed by aerial stems and leaves $\left(\mathrm{IC}_{50} 143.6 \pm 16.5 \mu \mathrm{g} / \mathrm{mL}\right.$ ), and the lowest in root extracts (Figure 1(b)). Extracts from the aerial parts of $H$. perforatum were analyzed by HPLC-DAD-ESI (electrospraynegative ionization). They showed the presence of two major naphthodianthrones identified as pseudohypericin and hypericin (Figure 2(a) and Table 1). Flower extracts had two additional compounds identified as protopseudohypericin and protohypericin. Phenolics and flavonoids abounded in H. perforatum extracts (Figure 2(b)). Chlorogenic acid and the quercetin glycosides rutin, hyperoside, isoquercitrin, miquelianin, acetyl hyperoside, and quercitrin, as well as free quercetin and biapigenin, were identified by HPLCDAD (ESI negative ionization) and DAD (Table 1). On the other hand, flower extracts contained four phloroglucinols (Figure 2(c)) that were identified by HPLC-DAD-MS (ESI negative and positive ionization) and DAD as hyperforin, adhyperforin, hyperfirin, and adhyperfirin (Table 1). The presence of these compounds (Figure 3 ) in the plant agrees with other results $[15,30,31]$. The content of the main components was determined by HPLC (Table 2). Concentration of pseudohypericin was higher than hypericin, whereas 


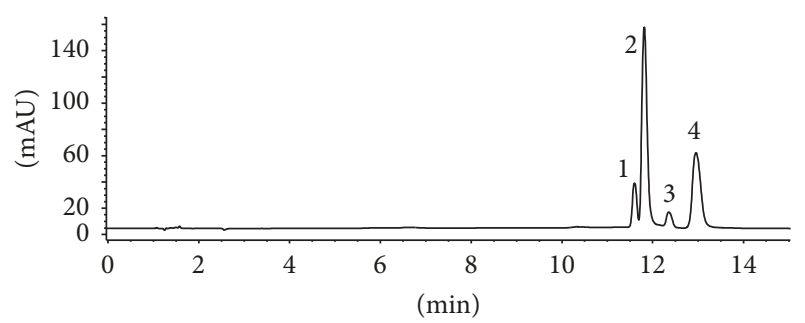

(a) $\lambda=590 \mathrm{~nm}$

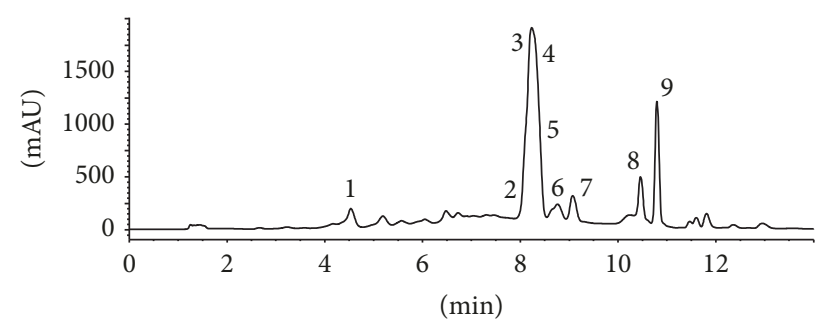

(b) $\lambda=265 \mathrm{~nm}$

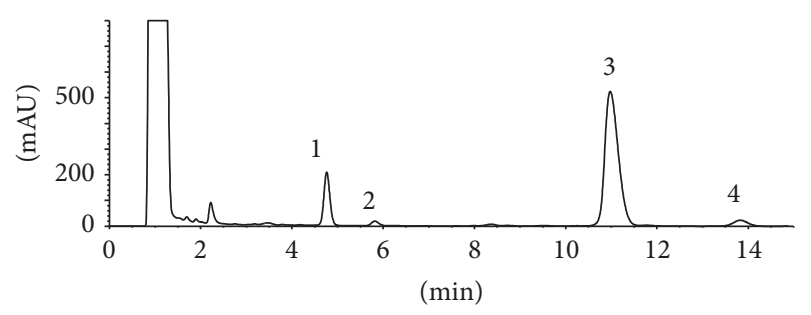

(c) $\lambda=280 \mathrm{~nm}$

FIgURE 2: HPLC chromatograms of extracts from $H$. perforatum flowers. (a) Detection of hypericins at $590 \mathrm{~nm}$. 1: protopseudohypericin; 2: pseudohypericin; 3: protohypericin; and 4: hypericin. (b) Detection of phenols and flavonoids at $265 \mathrm{~nm}$. 1: chlorogenic acid; 2: rutin; 3: hyperoside; 4: isoquercitrin; 5: miquelianin; 6: acetyl hyperoside; 7: quercitrin; 8: quercetin; and 9: biapigenin. (c) Detection of phloroglucinols at $280 \mathrm{~nm}$. 1: hyperfirin, 2: adhyperfirin; 3 : hyperforin; and 4 : adhyperforin.

protopseudohypericin and protohypericin were minor compounds $(0.4 \mu \mathrm{g} / \mathrm{mg}$ of protopseudohypericin and $0.17 \mu \mathrm{g} / \mathrm{mg}$ of protohypericin were detected in flowers). In the plant, the highest content of hypericins was found in flowers with significantly low levels detected in stems and absence in roots. Hyperforin was highly abundant in flowers $(27.2 \mu \mathrm{g} / \mathrm{mg})$, whereas the concentration in commercial preparations ranged from 0.36 to $2.4 \mu \mathrm{g} / \mathrm{mg}$. In flowers, adhyperforin (1.4 \pm $0.07 \mu \mathrm{g} / \mathrm{mg})$, hyperfirin $(4.2 \pm 0.02 \mu \mathrm{g} / \mathrm{mg})$, and adhyperfirin $(0.46 \pm 0.02 \mu \mathrm{g} / \mathrm{mg})$ also appeared. Flavonoids abounded in $H$. perforatum and most of them were quercetin glycosides (Figure 2(b)) whose presence was significantly higher in flowers than in other parts of the plant. The content of free quercetin in flowers was $2.0 \mu \mathrm{g} / \mathrm{mg}$, whereas a content of $6.7 \mu \mathrm{g} / \mathrm{mg}$ was determined in commercial preparations.

The inhibition of MAO-A by $H$. perforatum extracts indicates occurrence of inhibitors. Hypericins, hyperforin, and flavonoids are possible contributors to this inhibition and were evaluated as inhibitors (Figure 4). Hypericin inhibited MAO-A ( $\mathrm{IC}_{50}$ of $35.5 \pm 2.1 \mu \mathrm{M}$ or $17.9 \mu \mathrm{g} / \mathrm{mL}$ ) (Figure $4(\mathrm{a})$ ). From the concentration in Table 2, hypericin is a weak contributor to MAO inhibition in $H$. perforatum extracts. Indeed, the calculated content of hypericin at $\mathrm{IC}_{50}$ value in assays of flower extract (i.e., $63.6 \mu \mathrm{g} / \mathrm{mL}$ ) was $0.1 \mu \mathrm{g} / \mathrm{mL}$ which is low compared with $\mathrm{IC}_{50}$ of hypericin $(17.9 \mu \mathrm{g} / \mathrm{mL})$. Hyperforin did not inhibit MAO-A (Figure 4(b)). Quercetin inhibited human MAO-A (Figure 4(b)) with an $\mathrm{IC}_{50}$ value of $11.1 \pm 0.8 \mu \mathrm{M}$ (i.e., $3.36 \mu \mathrm{g} / \mathrm{mL}$ ). Then, quercetin was a better inhibitor than hypericin although its potency was still low to explain entire inhibition of extracts. Thus, the calculated content of quercetin at $\mathrm{IC}_{50}$ in assays of flower extract was $0.13 \mu \mathrm{g} / \mathrm{mL}$ which is lower than the $\mathrm{IC}_{50}$ of quercetin $(3.4 \mu \mathrm{g} / \mathrm{mL})$. When the fraction corresponding to quercetin glycosides and flavonoids (7-11 min, Figure 2(b)) was collected by RP-HPLC, it inhibited MAO-A ( $90 \%$ inhibition at $700 \mu \mathrm{g} / \mathrm{mL}$ extract) indicating a contribution of these compounds to $\mathrm{MAO}$ inhibition in $\mathrm{H}$. perforatum, probably by additive effects. Then, inhibition of MAO-A could arise from components such as quercetin and related flavonoids (i.e., quercetin glycosides) which are abundant in the plant. In addition, minor compounds not identified here could also contribute to MAO inhibition as major compounds in Table 2 do not explain whole inhibition.

Extracts from $P$. harmala seeds highly inhibited human MAO-A (Figure 5(a)) affording an $\mathrm{IC}_{50}$ value of $49.9 \pm$ $5.6 \mu \mathrm{g} / \mathrm{L}$. Chromatographic analysis indicated that inhibition was due to the presence of the $\beta$-carboline alkaloids, harmaline and harmine, that were identified by HPLC-DAD-MS (Figure 5(c)). The content of these alkaloids determined in seeds was $48.5 \mathrm{mg} / \mathrm{g}$ for harmaline and $40.0 \mathrm{mg} / \mathrm{g}$ for harmine (this means $2.4 \mathrm{ng} / \mathrm{mL}$ and $2.0 \mathrm{ng} / \mathrm{mL}$, resp., into assays at the $\mathrm{IC}_{50}$ ). Therefore, the inhibition potency of MAO-A by $P$. harmala seeds was 1274 times more potent than that of H. perforatum flowers. As shown in Figure 5(b), Lepidium meyenii root extracts did not inhibit human MAO-A. $L$. meyenii (maca) is a popular plant from the Andes highlands whose roots are increasingly used for its nutritional and medicinal properties as energizing and to improve mood and sexual performance $[28,32]$. Previous reports have indicated that they contain alkaloids including $\beta$-carbolines $[25,26]$ that might inhibit MAO. Analysis of extracts for $\beta$-carboline alkaloids gave $25 \mu \mathrm{g} / \mathrm{g}$ (maca powder) and $11.7 \mu \mathrm{g} / \mathrm{g}$ (capsules) of 1-methyl-1,2,3,4-tetrahydro- $\beta$-carboline-3-carboxylic acid as a major compound. This specific $\beta$-carboline is not an inhibitor of MAO-A $[8,11]$.

MAO generates hydrogen peroxide $\left(\mathrm{H}_{2} \mathrm{O}_{2}\right)$ that is involved in oxidative cell damage and pathological conditions $[1,3,4,33-36]$. Then, the inhibition of MAO may result in specific antioxidant actions [37]. In order to study the antioxidant activity associated with MAO inhibition, experiments were designed in this research which linked the activity of MAO-A with the oxidation of tetramethylbenzidine (TMB) by horseradish peroxidase (HRP) and the $\mathrm{H}_{2} \mathrm{O}_{2}$ produced during oxidative deamination catalyzed by MAO (Figure 6). $H$. perforatum and P. harmala extracts which inhibited MAOA as shown above highly decreased oxidation of TMB. In contrast, L. meyenii root (maca) extracts that did not inhibit MAO had a low antioxidant activity in this assay. Clorgyline which is a potent inhibitor of MAO-A highly decreased the oxidation of TMB when used as a control. The same happened 
TABLE 1: Compounds identified in H. perforatum.

\begin{tabular}{|c|c|c|}
\hline Compounds & ESI-neg. ion $(\mathrm{M}-\mathrm{H})^{-}$ & UV max (DAD) \\
\hline \multicolumn{3}{|l|}{ Naphthodianthrones } \\
\hline Pseudohypericin & 519 & 547,590 \\
\hline Hypericin & 503 & 547,590 \\
\hline Protopseudohypericin & 521 & 370,539 \\
\hline Protohypericin & 505 & 370,539 \\
\hline \multicolumn{3}{|l|}{ Phenolic comp. } \\
\hline Chlorogenic acid & 353 & 324 \\
\hline Rutin & 609 & 256,355 \\
\hline Hyperoside & 463 & 256,355 \\
\hline Isoquercitrin & 463 & 256,355 \\
\hline Miquelianin & 477 & 256,355 \\
\hline Acetyl hyperoside & 505 & 263,352 \\
\hline Quercitrin & 447 & 255,348 \\
\hline Quercetin & 301 & 255,369 \\
\hline Biapigenin & 537 & 268,331 \\
\hline \multicolumn{3}{|l|}{ Phloroglucinols } \\
\hline Hyperfirin $^{a}$ & 467 & 274 \\
\hline Adhyperfirin ${ }^{a}$ & 481 & 274 \\
\hline Hyperforin $^{\mathrm{a}}$ & 535 & 274 \\
\hline Adhyperforin $^{\mathrm{a}}$ & 549 & 274 \\
\hline
\end{tabular}

${ }^{\mathrm{a}}$ These compounds gave also their corresponding $(\mathrm{M}+\mathrm{H})^{+}$and $(\mathrm{M}+\mathrm{K})^{+}$ions under ESI-positive ionization.

TABLE 2: Content $(\mu \mathrm{g} / \mathrm{mg})^{1}$ of the main active components in $H$. perforatum samples.

\begin{tabular}{|c|c|c|c|c|}
\hline H. perforatum samples & Pseudohypericin & Hypericin & Hyperforin & Quercetin \\
\hline \multicolumn{5}{|l|}{ Plant } \\
\hline Stems (top) & $0.25 \pm 0.03^{\mathrm{a}}$ & $0.11 \pm 0.01^{\mathrm{a}}$ & $1.48 \pm 0.3^{\mathrm{a}}$ & $0.28 \pm 0.12^{\mathrm{a}}$ \\
\hline Stems (central) & $0.1 \pm 0.04^{\mathrm{a}}$ & $0.04 \pm 0.01^{\mathrm{a}}$ & $0.59 \pm 0.16^{\mathrm{a}}$ & $0.19 \pm 0.01^{\mathrm{a}}$ \\
\hline Roots & - & - & $0.77 \pm 0.1^{\mathrm{a}}$ & - \\
\hline Flowers & $2.78 \pm 0.7^{\mathrm{b}}$ & $1.58 \pm 0.31^{\mathrm{b}}$ & $27.2 \pm 0.6^{\mathrm{b}}$ & $2.04 \pm 0.08^{b}$ \\
\hline \multicolumn{5}{|l|}{ Commercial prep. } \\
\hline Herbs & $0.51 \pm 0.05^{\mathrm{a}}$ & $0.11 \pm 0.01^{\mathrm{a}}$ & $1.18 \pm 0.03^{\mathrm{a}}$ & $0.71 \pm 0.4^{\mathrm{a}}$ \\
\hline Capsules & $2.41 \pm 0.2^{\mathrm{b}}$ & $0.83 \pm 0.1^{\mathrm{b}}$ & $2.42 \pm 0.01^{b}$ & $2.4 \pm 0.9^{\mathrm{a}}$ \\
\hline Tablets & $2.39 \pm 0.2^{\mathrm{b}}$ & $2.11 \pm 0.2^{c}$ & $0.36 \pm 0.1^{\mathrm{c}}$ & $6.7 \pm 1.7^{\mathrm{b}}$ \\
\hline
\end{tabular}

Significant differences $(p<0.05)$ for a compound within a group are indicated with different letters. ${ }^{1} \mu \mathrm{g}$ of compound/mg of plant tissue for plants parts and herbs or $\mathrm{mg}$ of powder in capsules and tablets.

with the presence of catalase in the media that removes $\mathrm{H}_{2} \mathrm{O}_{2}$ generated by MAO-A. Therefore, these results indicate that $H$. perforatum and $P$. harmala extracts afforded specific antioxidant actions associated with a lower production of $\mathrm{H}_{2} \mathrm{O}_{2}$ by inhibition of MAO.

H. perforatum improves mood disorders and depression $[17,18,38]$. As shown here, it contains compounds such as hyperforin, hypericins, and flavonoids responsible for antidepressant effects (Figure 2 and Table 2). However, the specific mechanism for antidepressant action is not completely understood. The most accepted mechanism is inhibition of monoamine reuptake [23, 24, 39, 40]. However, some studies suggest a combination of mechanisms and synergistic effects $[17,41]$. P. harmala exerts numerous biological and pharmacological actions. Their seeds are increasingly used for recreational purposes owing to their psychoactive and neuroactive effects [14]. The inhibition of human MAO$\mathrm{A}$ is an established mechanism for antidepressant action [1]. Both irreversible and reversible inhibitors of MAO-A (e.g., phenelzine and moclobemide) are successfully used as antidepressants. In this study, $H$. perforatum extracts inhibited human MAO-A. However, this inhibition was moderate. It was more than one thousand times lower than that of $P$. harmala seed extracts. Sacher et al. have reported that the occupancy of MAO-A sites into the human brain determined by PET imaging with ${ }^{11} \mathrm{C}$-harmine binding (i.e., the same $\beta$-carboline responsible for MAO inhibition in P. harmala) was high for a reversible inhibitor of MAO such as moclobemide but low for $H$. perforatum extract (St. John's wort) [42]. This means that the inhibitors of MAO-A 
<smiles>[R]Cc1cc(O)c2c(=O)c3c(O)cc(O)c4c5c(O)cc(O)c6c(=O)c7c(O)cc(C)c8c1c2c(c34)c(c78)c65</smiles>

Pseudohypericin $(\mathrm{R}=\mathrm{OH})$ Hypericin $(\mathrm{R}=\mathrm{H})$<smiles></smiles>

Protopseudohypericin $(\mathrm{R}=\mathrm{OH})$ Protohypericin $(\mathrm{R}=\mathrm{H})$<smiles>O=c1c(O)c(-c2ccc(O)c(O)c2)oc2cc(O)cc(O)c12</smiles>

Quercetin $(\mathrm{R}=\mathrm{H})$ Hyperoside $(\mathrm{R}=\mathrm{Gal})$ Quercitrin $(\mathrm{R}=\mathrm{Rha})$ Rutin ( $=$ Glu-Rha) Isoquercitrin $(\mathrm{R}=\mathrm{Glu})$

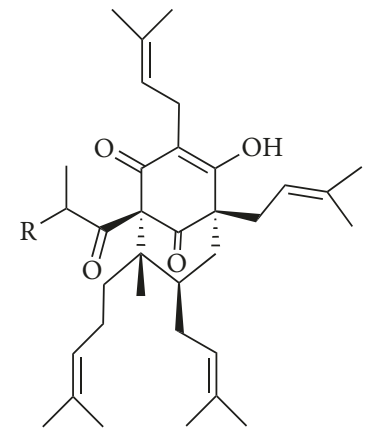

Hyperforin $\left(\mathrm{R}=\mathrm{CH}_{3}\right)$ Adhyperforin $\left(\mathrm{R}=\mathrm{CH}_{2} \mathrm{CH}_{3}\right)$<smiles></smiles>

Hyperfirin $\left(\mathrm{R}=\mathrm{CH}_{3}\right)$ Adhyperfirin $\left(\mathrm{R}=\mathrm{CH}_{2} \mathrm{CH}_{3}\right)$

Figure 3: Structures of compounds identified in H. perforatum: hypericins, quercetin, and quercetin flavonoids and phloroglucinols (hyperforin, adhyperforin, hyperfirin, and adhyperfirin).

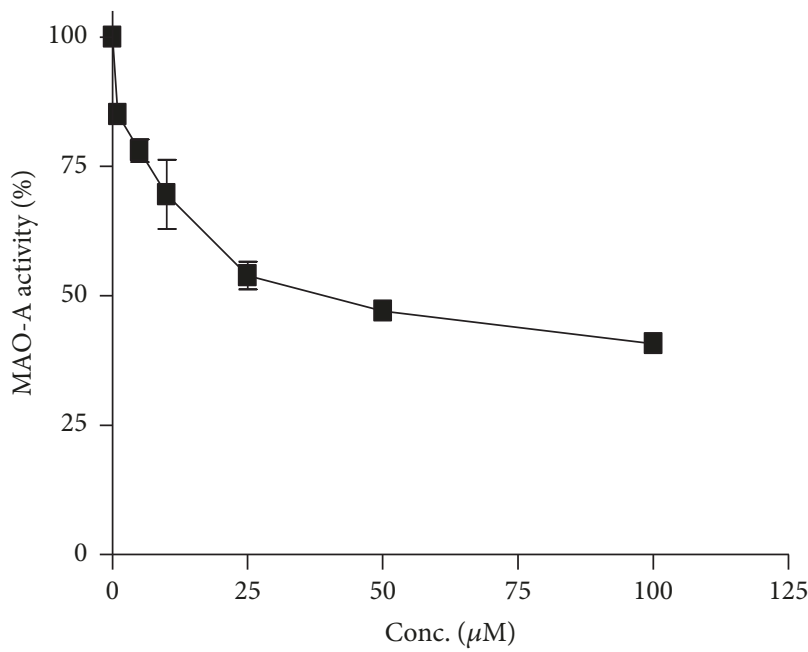

(a)

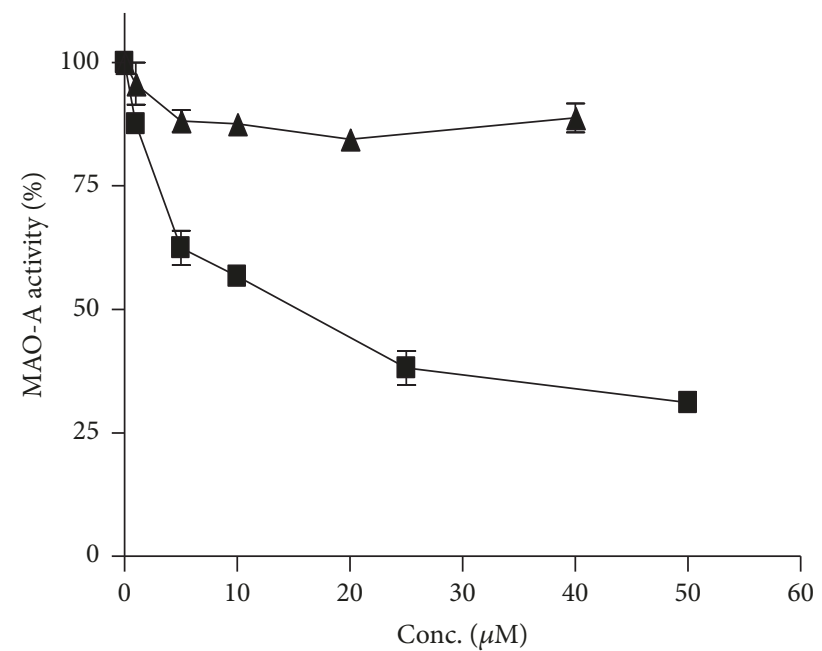

(b)

FIGURE 4: Inhibition of human monoamine oxidase-A (MAO-A) by active components of $H$. perforatum: hypericin (a) and quercetin ( $\mathbf{\square})$ and hyperforin ( $\mathbf{\Delta})(\mathrm{b})$.

in $H$. perforatum do not bind efficiently to active sites of MAO-A in the brain in contrast to the $\beta$-carboline harmine. The inhibitors of MAO-A in $H$. perforatum are flavonoids such as quercetin and their glycosides and the levels of these compounds that reach the brain might not be enough to occupy the sites of MAO-A in the brain and inhibit the enzyme [43]. In contrast, the inhibitors of $P$. harmala are $\beta$-carboline alkaloids including harmine and harmaline which have a very good brain penetration, bind with high affinity to MAO sites, and exhibit antidepressant effects [4446]. Therefore, $P$. harmala could afford antidepressant effects by MAO inhibition. In this regard, it could be of interest to 


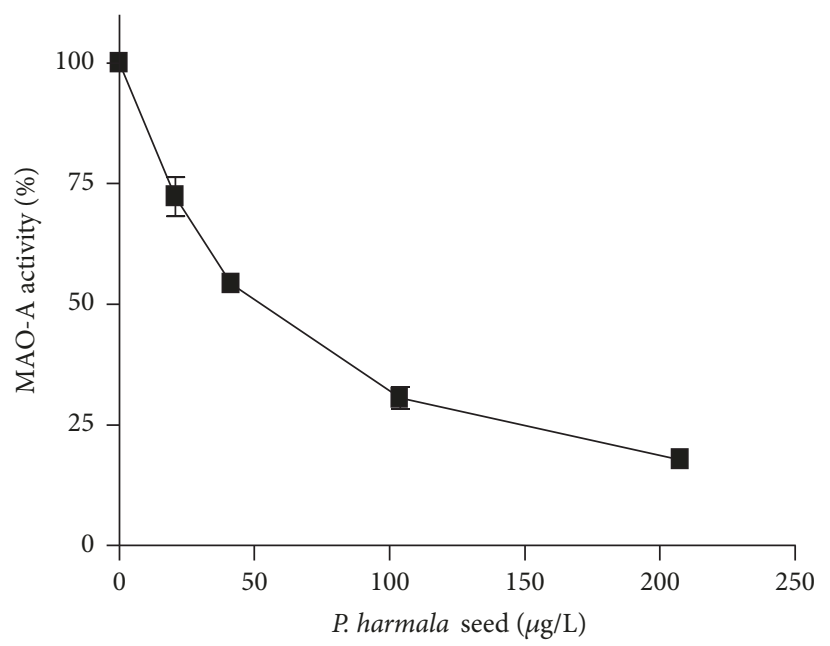

(a)

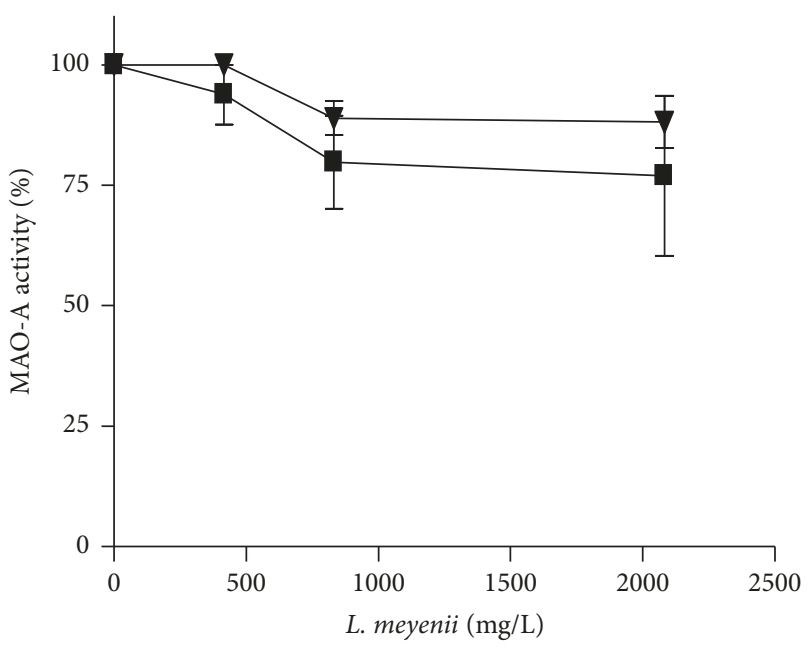

(b)

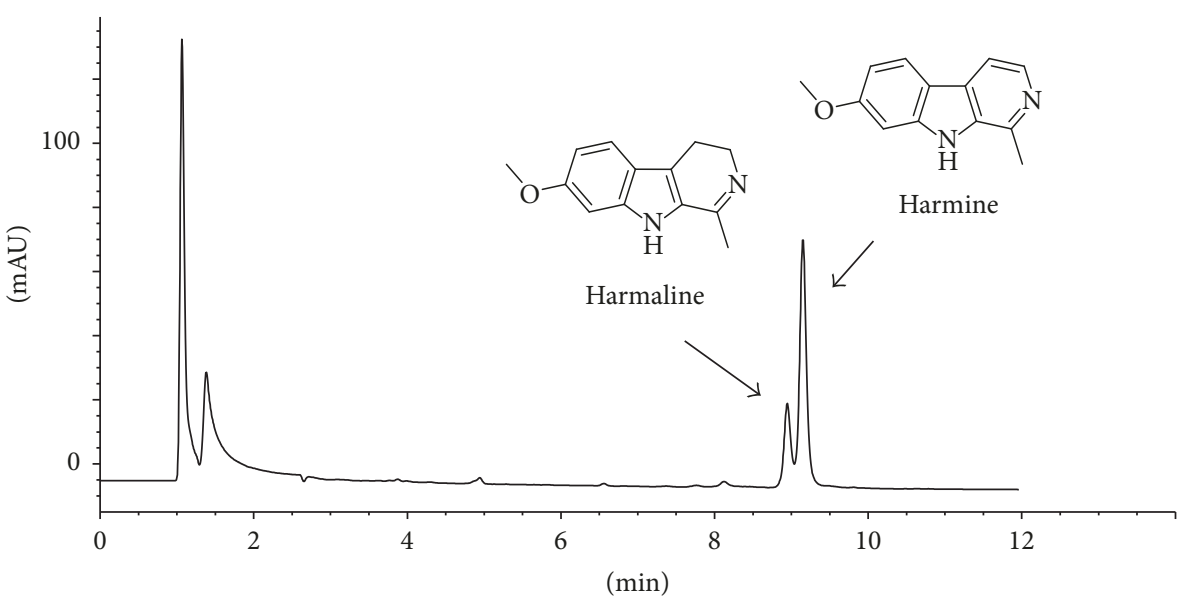

(c)

FIGURE 5: Inhibition of human monoamine oxidase-A (MAO-A) by P. harmala seed (a) and L. meyenii root (maca) extracts (b) (capsules, $\boldsymbol{\nabla}$ and powder, $\mathbf{\square})$. (c) HPLC chromatogram of $P$. harmala seed extract which potently inhibited human MAO-A. Absorbance detection at $254 \mathrm{~nm}$. Compounds identified are harmaline $\left(\mathrm{m} / z\right.$ at $215(\mathrm{M}+\mathrm{H})^{+}, \mathrm{UV}_{\max }$ at $\left.375 \mathrm{~nm}\right)$ and harmine $\left(\mathrm{m} / z\right.$ at $213(\mathrm{M}+\mathrm{H})^{+}, \mathrm{UV}$ max at 245 and $322 \mathrm{~nm})$.

investigate the antidepressant effects of $H$. perforatum and $P$. harmala alone and in combination as they have different mechanisms of action.

The inhibition of MAO-A by $H$. perforatum and $P$. harmala extracts may contribute to other biological effects of these plants such as antioxidant actions and adverse pharmacological reactions. Extracts of these plants exert neuroprotective and anti-inflammatory effects which have been related to antioxidant activity $[6,9,47-50]$. In this regard by using a new procedure, results in this work have evidenced that $H$. perforatum and $P$. harmala extracts show antioxidant activity associated with the inhibition of MAO (lower production of $\mathrm{H}_{2} \mathrm{O}_{2}$ ). On the other hand, one of the major limitations to the use of these plants is their potential for producing adverse interactions with other herbs, foods, and drugs $[17,20,21,27]$. The inhibition of MAOA may trigger adverse effects under certain circumstances $[1,14]$.

\section{Conclusions}

Extracts from $H$. perforatum inhibited human MAO-A, and extracts from flowers were the most potent inhibitors. They were studied by HPLC-DAD-MS and contained pseudohypericin, hypericin, hyperforin, adhyperforin, hyperfirin, and flavonoids. The highest content of these compounds appeared in flowers. Hypericin was a weak inhibitor of MAOA; hyperforin did not inhibit the enzyme and quercetin was a moderate inhibitor. The fraction of quercetin glycosides and flavonoids contributed to MAO inhibition. P. harmala seed extracts highly inhibited MAO-A and its potency of inhibition was more than a thousand times higher than $H$. perforatum extracts owing to its content in harmaline and harmine alkaloids. L. meyenii root (maca) extracts did not inhibit MAO-A. The inhibition of MAO-A may not explain the entire CNS effects attributed to $H$. perforatum but it is expected to contribute to these actions in $P$. harmala. These plants exert antioxidant effects. By using a new method this 


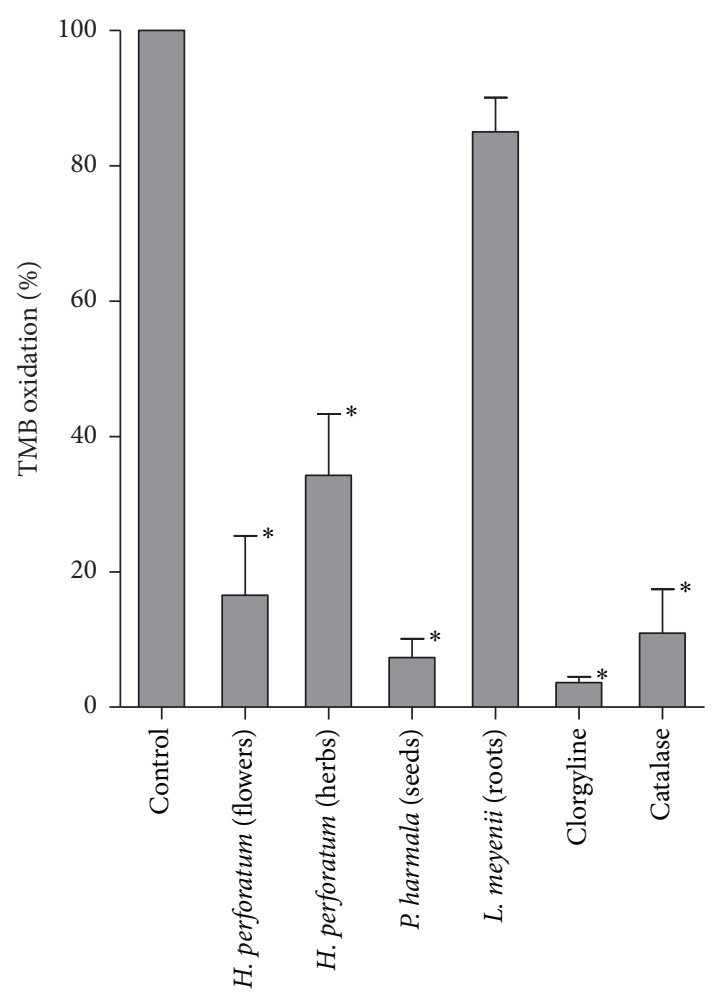

FIgURE 6: Antioxidant activity associated with MAO inhibition in assays coupling activity of MAO-A with the subsequent oxidation of tetramethylbenzidine (TMB) in the presence $\mathrm{H}_{2} \mathrm{O}_{2}$ generated in the reaction of $\mathrm{MAO}$, and horseradish peroxidase (HRP). The graph shows the oxidation of TMB to diimine (absorbance at $450 \mathrm{~nm}$ ) in control assays (100\%), and in the presence of $H$. perforatum (herbs and flower extracts, $800 \mu \mathrm{g} / \mathrm{mL}$ ), P. harmala seed extracts $(0.8 \mu \mathrm{g} / \mathrm{mL})$, L. meyenii root (maca) extracts $(800 \mu \mathrm{g} / \mathrm{mL})$, clorgyline (a standard inhibitor of MAO-A) $(25 \mu \mathrm{M})$, and catalase $(100 \mu \mathrm{g} / \mathrm{mL})$. *Significant differences $(p<0.01)$ compared to controls.

work have evidenced that $P$. harmala and $H$. perforatum extracts exhibit antioxidant activity associated with the inhibition of MAO.

\section{Conflicts of Interest}

The authors declare no competing financial interest.

\section{Acknowledgments}

The authors are grateful to MINECO-FEDER (SAF201566690-R and SAF2015-68580-C2-R) and CSIC (Spain) (Project 200470E658) for supporting this work. The authors are grateful also to Marta Aguilar Preiss for technical assistance and to Dr. V. Arán for helping with plant identification and selection.

\section{References}

[1] M. B. H. Youdim, D. Edmondson, and K. F. Tipton, "The therapeutic potential of monoamine oxidase inhibitors," Nature Reviews Neuroscience, vol. 7, no. 4, pp. 295-309, 2006.
[2] T. Herraiz, H. Guillén, and J. Galisteo, "Metabolite Profile Resulting from the Activation/Inactivation of 1-Methyl-4phenyl-1,2,3,6-tetrahydropyridine and 2-Methyltetrahydro- $\beta$ carboline by Oxidative Enzymes," BioMed Research International, vol. 2013, Article ID 248608, 10 pages, 2013.

[3] T. Herraiz and H. Guillén, "Inhibition of the bioactivation of the neurotoxin MPTP by antioxidants, redox agents and monoamine oxidase inhibitors," Food and Chemical Toxicology, vol. 49, no. 8, pp. 1773-1781, 2011.

[4] G. Cohen and N. Kesler, "Monoamine oxidase and mitochondrial respiration," Journal of Neurochemistry, vol. 73, no. 6, pp. 2310-2315, 1999.

[5] M. S. Farahani, R. Bahramsoltani, M. H. Farzaei, M. Abdollahi, and R. Rahimi, "Plant-derived natural medicines for the management of depression: An overview of mechanisms of action," Reviews in the Neurosciences, vol. 26, no. 3, pp. 305-321, 2015.

[6] M. A. Gómez del Rio, M. I. Sánchez-Reus, I. Iglesias et al., "Neuroprotective properties of standardized extracts of hypericum perforatum on rotenone model of parkinson's disease," CNS and Neurological Disorders - Drug Targets, vol. 12, no. 5, pp. 665-679, 2013.

[7] T. Herraiz, "Identification and occurrence of $\beta$-carboline alkaloids in raisins and inhibition of monoamine oxidase (MAO)," Journal of Agricultural and Food Chemistry, vol. 55, no. 21, pp. 8534-8540, 2007.

[8] T. Herraiz and C. Chaparro, "Human monoamine oxidase enzyme inhibition by coffee and $\beta$-carbolines norharman and harman isolated from coffee," Life Sciences, vol. 78, no. 8, pp. 795-802, 2006.

[9] M. Mohanasundari and M. Sabesan, "Modulating effect of Hypericum perforatum extract on astrocytes in MPTP induced Parkinson's disease in mice," European Review for Medical and Pharmacological Sciences, vol. 11, no. 1, pp. 17-20, 2007.

[10] D. O. Kennedy and E. L. Wightman, "Herbal extracts and phytochemicals: plant secondary metabolites and the enhancement of human brain function," Advances in Nutrition, vol. 2, no. 1, pp. 32-50, 2011.

[11] T. Herraiz and C. Chaparro, "Analysis of monoamine oxidase enzymatic activity by reversed-phase high performance liquid chromatography and inhibition by $\beta$-carboline alkaloids occurring in foods and plants," Journal of Chromatography A, vol. 1120, no. 1-2, pp. 237-243, 2006.

[12] A. K. Jäger, B. Gauguin, J. Andersen, A. A. Ersen, and L. Gudiksen, "Screening of plants used in Danish folk medicine to treat depression and anxiety for affinity to the serotonin transporter and inhibition of MAO-A," Journal of Ethnopharmacology, vol. 145, no. 3, pp. 822-825, 2013.

[13] Y. Bandaruk, R. Mukai, T. Kawamura, H. Nemoto, and J. Terao, "Evaluation of the inhibitory effects of quercetin-related flavonoids and tea catechins on the monoamine oxidase-A reaction in mouse brain mitochondria," Journal of Agricultural and Food Chemistry, vol. 60, no. 41, pp. 10270-10277, 2012.

[14] T. Herraiz, D. González, C. Ancín-Azpilicueta, V. J. Arán, and H. Guillén, " $\beta$-carboline alkaloids in Peganum harmala and inhibition of human monoamine oxidase (MAO)," Food and Chemical Toxicology, vol. 48, no. 3, pp. 839-845, 2010.

[15] B. A. Silva, F. Ferreres, J. O. Malva, and A. C. P. Dias, "Phytochemical and antioxidant characterization of Hypericum perforatum alcoholic extracts," Food Chemistry, vol. 90, no. 1-2, pp. 157-167, 2005.

[16] I. E. Orhan, M. Kartal, A. R. Gülpinar et al., "Assessment of antimicrobial and antiprotozoal activity of the olive oil macerate 
samples of Hypericum perforatum and their LC-DAD-MS analyses," Food Chemistry, vol. 138, no. 2-3, pp. 870-875, 2013.

[17] E. Russo, F. Scicchitano, B. J. Whalley et al., "Hypericum perforatum: Pharmacokinetic, mechanism of action, tolerability, and clinical drug-drug interactions," Phytotherapy Research, vol. 28, no. 5, pp. 643-655, 2014.

[18] S. Kasper, F. Caraci, B. Forti, F. Drago, and E. Aguglia, "Efficacy and tolerability of Hypericum extract for the treatment of mild to moderate depression," European Neuropsychopharmacology, vol. 20, no. 11, pp. 747-765, 2010.

[19] K. Linde, L. Kriston, G. Rücker et al., "Efficacy and acceptability of pharmacological treatments for depressive disorders in primary care: Systematic review and network meta-analysis," Annals of Family Medicine, vol. 13, no. 1, pp. 69-79, 2015.

[20] F. Borrelli and A. A. Izzo, "Herb-drug interactions with St John's Wort (hypericum perforatum): an update on clinical observations," The AAPS Journal, vol. 11, no. 4, pp. 710-727, 2009.

[21] C. L. Hoban, R. W. Byard, and I. F. Musgrave, "A comparison of patterns of spontaneous adverse drug reaction reporting with St. John's Wort and fluoxetine during the period 2000-2013," Clinical and Experimental Pharmacology and Physiology, vol. 42, no. 7, pp. 747-751, 2015.

[22] J. R. T. Davidson, K. M. Gadde, J. A. Fairbank et al., "Effect of Hypericum perforatum (St John's wort) in major depressive disorder-a randomized controlled trial," The Journal of the American Medical Association, vol. 287, no. 14, pp. 1807-1814, 2002.

[23] W. E. Muller, A. Singer, M. Wonnemann, U. Hafner, M. Rolli, and C. Schafer, "Hyperforin represents the neurotransmitter reuptake inhibiting constituent of Hypericum extract," Pharmacopsychiatry, vol. 31, pp. 16-21, 1998.

[24] A. Paulke, M. Noldner, M. Schubert-Zslavecz, and M. Wurglics, "St. John's wort flavonols and their metabolites show antidepressant activity and accumulate in brain after multiple oral doses," Pharmazie, vol. 63, no. 4, pp. 296-302, 2008.

[25] Y. Wang, Y. Wang, B. McNeil, and L. M. Harvey, "Maca: An Andean crop with multi-pharmacological functions," Food Research International, vol. 40, no. 7, pp. 783-792, 2007.

[26] S. Piacente, V. Carbone, A. Plaza, A. Zampelli, and C. Pizza, "Investigation of the tuber constituents of maca (Lepidium meyenii Walp.)," Journal of Agricultural and Food Chemistry, vol. 50, no. 20, pp. 5621-5625, 2002.

[27] G. Frison, D. Favretto, F. Zancanaro, G. Fazzin, and S. D. Ferrara, "A case of $\beta$-carboline alkaloid intoxication following ingestion of Peganum harmala seed extract," Forensic Science International, vol. 179, no. 2-3, pp. e37-e43, 2008.

[28] G. F. Gonzales, C. Gonzales, and C. Gonzales-Castañeda, "Lepidium meyenii (Maca): a plant from the highlands of Peru-from tradition to science," Forschende Komplementärmedizin, vol. 16, no. 6, pp. 373-380, 2009.

[29] T. Herraiz, "Tetrahydro-beta-carboline-3-carboxylic acid compounds in fish and meat: Possible precursors of co-mutagenic beta-carbolines norharman and harman in cooked foods," Food Additives and Contaminants, vol. 17, no. 10, pp. 859-866, 2000.

[30] A. Tolonen, A. Hohtola, and J. Jalonen, "Fast high-performance liquid chromatographic analysis of naphthodianthrones and phloroglucinols from Hypericum perforatum extracts," Phytochemical Analysis, vol. 14, no. 5, pp. 306-309, 2003.

[31] E. C. Tatsis, S. Boeren, V. Exarchou, A. N. Troganis, J. Vervoort, and I. P. Gerothanassis, "Identification of the major constituents of Hypericum perforatum by LC/SPE/NMR and/or LC/MS," Phytochemistry, vol. 68, no. 3, pp. 383-393, 2007.

[32] M. Stone, A. Ibarra, M. Roller, A. Zangara, and E. Stevenson, "A pilot investigation into the effect of maca supplementation on physical activity and sexual desire in sportsmen," Journal of Ethnopharmacology, vol. 126, no. 3, pp. 574-576, 2009.

[33] B. Halliwell and J. M. Gutteridge, Free radicals in biology and medicine, Oxford University Press, 1999.

[34] T. Herraiz and J. Galisteo, "Naturally-occurring tetrahydro- $\beta$ carboline alkaloids derived from tryptophan are oxidized to bioactive $\beta$-carboline alkaloids by heme peroxidases," Biochemical and Biophysical Research Communications, vol. 451, no. 1, pp. 42-47, 2014.

[35] N. Kaludercic, J. Mialet-Perez, N. Paolocci, A. Parini, and F. Di Lisa, "Monoamine oxidases as sources of oxidants in the heart," Journal of Molecular and Cellular Cardiology, vol. 73, pp. 34-42, 2014.

[36] J. K. Mallajosyula, D. Kaur, S. J. Chinta et al., "MAO-B elevation in mouse brain astrocytes results in Parkinson's pathology," PLoS ONE, vol. 3, no. 2, Article ID e1616, 2008.

[37] T. Herraiz, A. Flores, and L. Fernández, "Analysis of monoamine oxidase (MAO) enzymatic activity by high-performance liquid chromatography-diode array detection combined with an assay of oxidation with a peroxidase and its application to MAO inhibitors from foods and plants," Journal of Chromatography B: Analytical Technologies in the Biomedical and Life Sciences, vol. 1073, pp. 136-144, 2018.

[38] I. A. Bukhari and A. Dar, "Behavioral profile of Hypericum perforatum (St. John's Wort) extract. A comparison with standard antidepressants in animal models of depression," European Review for Medical and Pharmacological Sciences, vol. 17, no. 8, pp. 1082-1089, 2013.

[39] X.-J. Zhai, F. Chen, C. Chen, C.-R. Zhu, and Y.-N. Lu, "LCMS/MS based studies on the anti-depressant effect of hypericin in the chronic unpredictable mild stress rat model," Journal of Ethnopharmacology, vol. 169, pp. 363-369, 2015.

[40] J. M. Cott, "In vitro receptor binding and enzyme inhibition by an extract of Hypericum perforatum," Psychopharmakotherapie, vol. 5, no. 3, pp. 51-55, 1998.

[41] W. E. Muller, M. Rolli, C. Schafer, and U. Hafner, "Effects of hypericum extract (LI 160) in biochemical models of antidepressant activity," Pharmacopsychiatry, vol. 30, pp. 102-107, 1997.

[42] J. Sacher, S. Houle, J. Parkes et al., "Monoamine oxidase A inhibitor occupancy during treatment of major depressive episodes with moclobemide or St. John's wort: an C-11 -harmine PET study," Journal of Psychiatry and Neuroscience, vol. 36, no. 6, pp. 375-382, 2011.

[43] S. Yoshino, A. Hara, H. Sakakibara et al., "Effect of quercetin and glucuronide metabolites on the monoamine oxidase-A reaction in mouse brain mitochondria," Nutrition, vol. 27, no. 7-8, pp. 847-852, 2011.

[44] D. Farzin and N. Mansouri, "Antidepressant-like effect of harmane and other $\beta$-carbolines in the mouse forced swim test," European Neuropsychopharmacology, vol. 16, no. 5, pp. 324-328, 2006.

[45] T. Herraiz, " $\beta$-Carboline alkaloids," in Bioactive compounds in foods, J. Gilbert and H. Z. Senyuva, Eds., pp. 199-223, Blackwell Publishing, 2008.

[46] T. Herraiz, "N-methyltetrahydropyridines and pyridinium cations as toxins and comparison with naturally-occurring alkaloids," Food and Chemical Toxicology, vol. 97, pp. 23-39, 2016. 
[47] K. D. P. Hammer and D. F. Birt, "Evidence for contributions of interactions of constituents to the anti-inflammatory activity of hypericum perforatum," Critical Reviews in Food Science and Nutrition, vol. 54, no. 6, pp. 781-789, 2014.

[48] B. A. Silva, J. O. Malva, and A. C. P. Dias, "St. John's Wort (Hypericum perforatum) extracts and isolated phenolic compounds are effective antioxidants in several in vitro models of oxidative stress," Food Chemistry, vol. 110, no. 3, pp. 611-619, 2008.

[49] S. Bensalem, J. Soubhye, I. Aldib et al., "Inhibition of myeloperoxidase activity by the alkaloids of Peganum harmala L. (Zygophyllaceae)," Journal of Ethnopharmacology, vol. 154, no. 2, pp. 361-369, 2014.

[50] Y. Zou, Y. Lu, and D. Wei, "Antioxidant activity of a flavonoidrich extract of Hypericum perforatum L. in vitro," Journal of Agricultural and Food Chemistry, vol. 52, no. 16, pp. 5032-5039, 2004. 


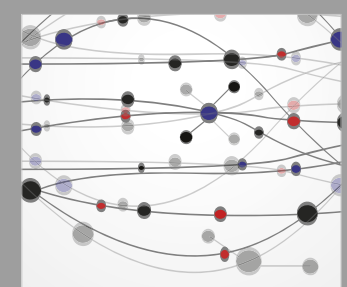

The Scientific World Journal
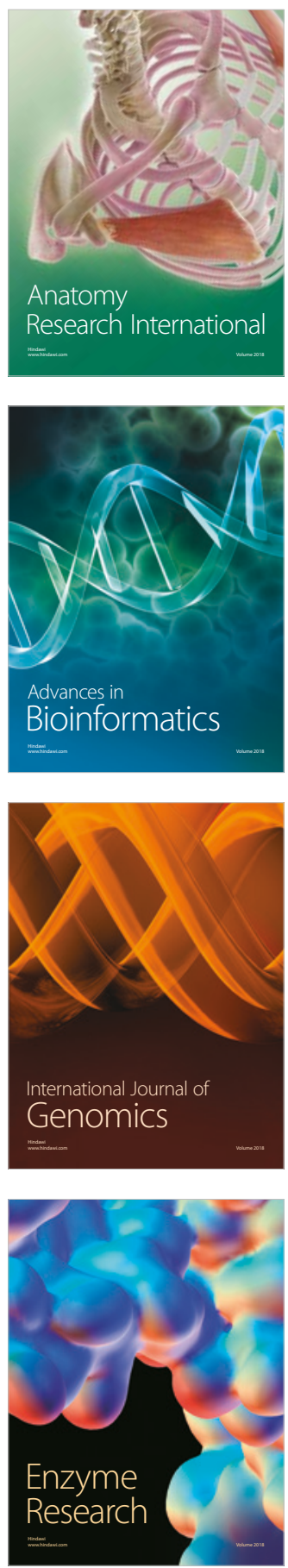
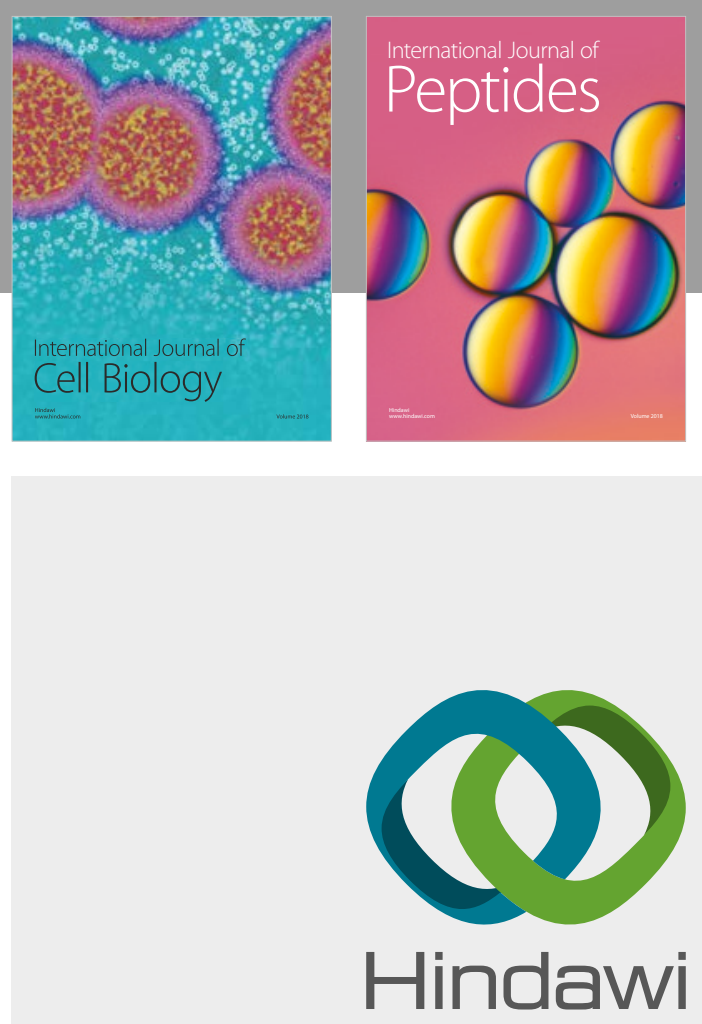

Submit your manuscripts at

www.hindawi.com
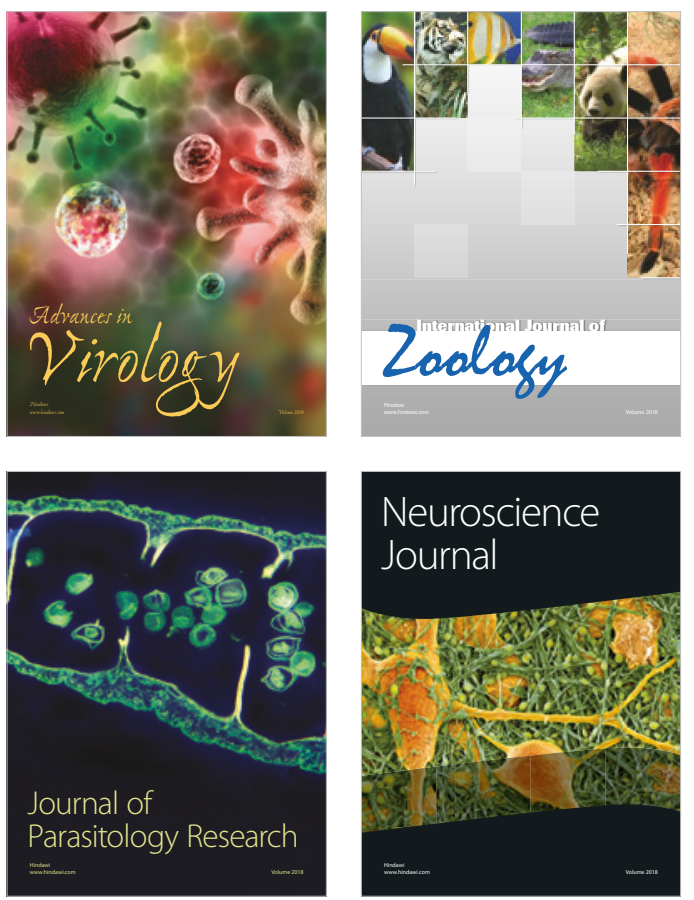
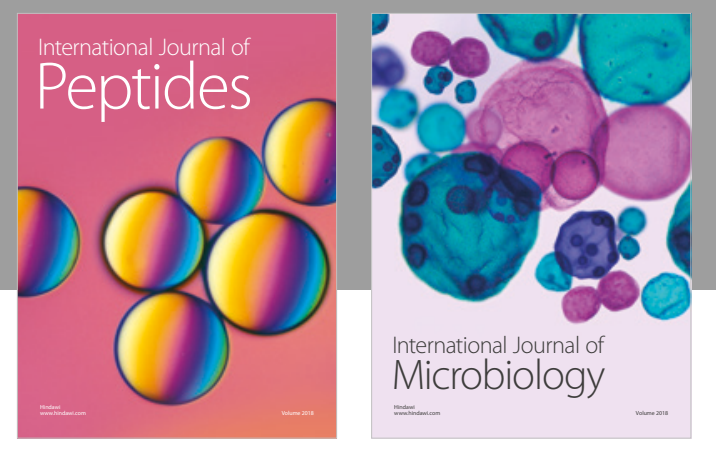

nternational Journal of Microbiology
Journal of
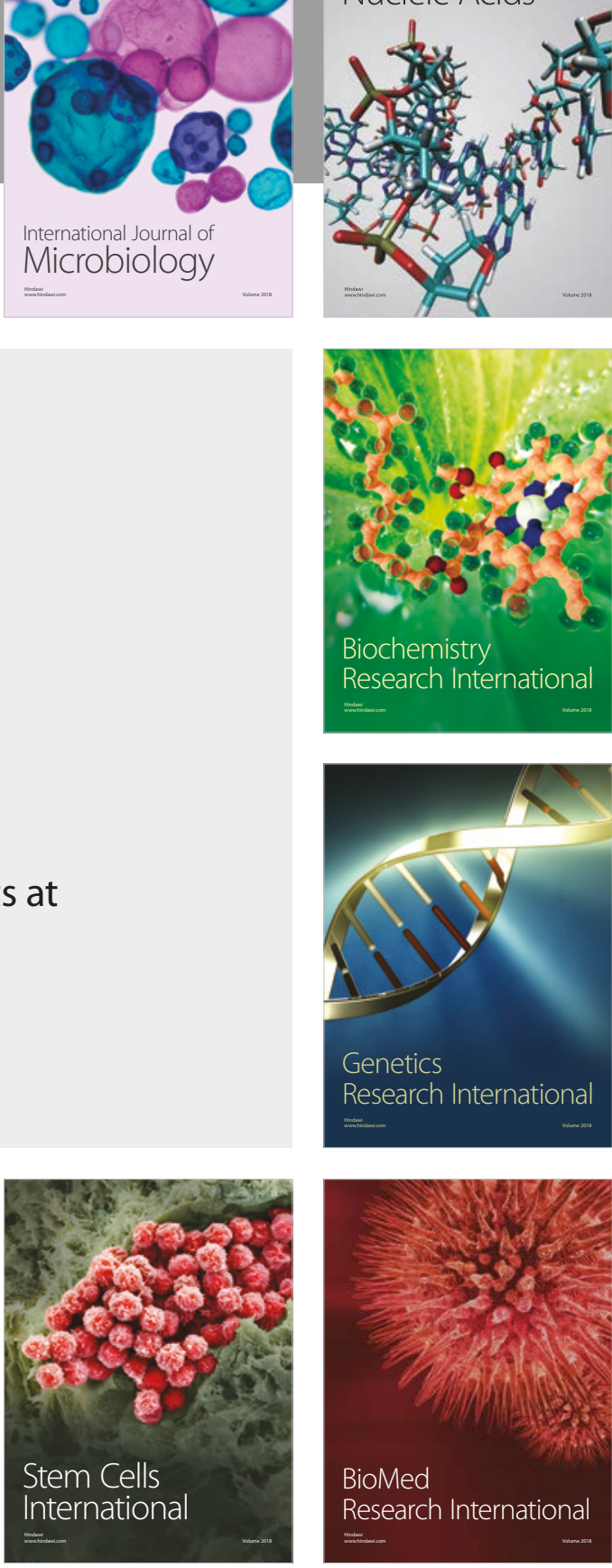
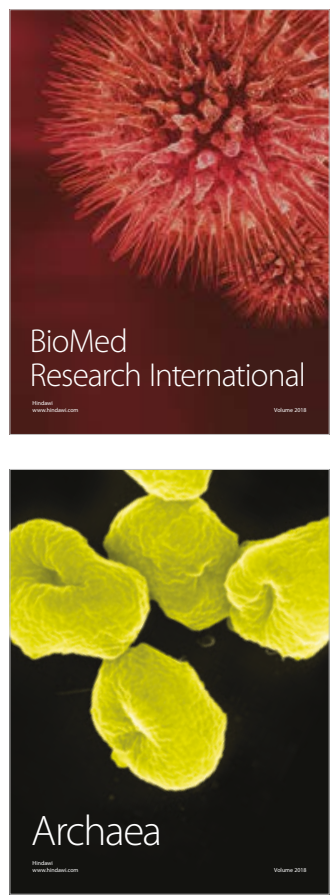